\title{
The Scenario of Carbonaceous Aerosols and Total Solar Radiation in Two Cities in Nepal
}

\author{
R.K. Sharma ${ }^{1, *}$, B.K. Bhattarai ${ }^{1}$, B.K. Sapkota ${ }^{1}$, M.B. Gewali ${ }^{2}$ and B. Kjeldstad ${ }^{3}$ \\ ${ }^{1}$ Pulchowk Campus Institute of Engineering, Tribhuvan University, Lalitpur, Nepal \\ ${ }^{2}$ Central Department of Chemistry, Tribhuvan University, Kirtipur, Kathmandu, Nepal \\ ${ }^{3}$ Depart of Physics, Norwegian University of Science and Technology, Trondheim, Norway
}

\begin{abstract}
Measurement of elemental carbon (EC) and black carbon (BC) aerosols was carried out using AE-31, 7 channel aethalometer at Kathmandu and Biratnagar; two mega cities of Nepal, for five months, January to May 2011 to study its temporal and spatial variation. Total solar radiation was also monitored using Kipp and Zonen CMP 6 pyranometer. Monthly concentration variation for EC and BC was distinct in both study sites. At Biratnagar, monthly EC concentration varies from $3.3-20.7 \mu \mathrm{g} / \mathrm{m}^{3}$ while in Kathmandu it varies between $6.0-13.7 \mu \mathrm{g} / \mathrm{m}^{3}$. Similarly, BC monthly concentration ranges from $3.3-20.1 \mu \mathrm{g} / \mathrm{m}^{3}$ and $7.0-14.9 \mu \mathrm{g} / \mathrm{m}^{3}$ respectively. It was found that both EC and BC were highest during January in both the sites and it decreases gradually. Monthly average solar radiation shows a maximum value in May and minimum in January. A distinct anti-correlation between monthly average carbonaceous aerosols and total solar radiation was observed. Moreover, there was a pronounced diurnal variation of both carbonaceous aerosols $E C$ and $B C$ in the sites with two high peaks one in the morning at about 9:00 and another at late evening 20:00 local time with minimum concentration in the afternoon. The nature of peaks were different at two sites. Biratnagar shows a larger evening peak while Kathmandu shows in the morning inferring heavy domestic and industrial fuel consuming activities in evening and morning respectively. In addition to this, daily and monthly concentration of EC was more than BC at Biratnagar reflecting slightly more biomass fuel consumption than fossil fuel for domestic, industrial and other urban activities. In contrast to this, Kathmandu shows more domination of fossil fuel than biofuel because of reverse order concentration of carbonaceous aerosols. Total solar radiation also shows apparent diurnal variation in both sites with the highest value at around noon time.
\end{abstract}

Keywords: Carbonaceous aerosol, Black carbon, Elemental carbon, Aethalometer, Total solar radiation.

\section{INTRODUCTION}

Carbonaceous aerosol is the main constituent (20$80 \%$ of fine particle) in the particulate matter [1]. The classification methods of carbonaceous aerosol vary with different detection methods [2]. Black carbon (BC) is defined as the carbonaceous material having intense black or dark color and it absorbs visible light efficiently $[3,4]$. Often a smaller fraction of atmospheric BC is elemental carbon (EC) and most of it consists of highly polymerized organic material having rather low hydrogen to carbon and oxygen to carbon ratios [3]. The contribution of EC can be highly increased close to its source like traffic. BC and EC both are the major anthropogenic components of atmospheric aerosols. About one half of the global $B C$ aerosol emission is estimated to rise from fossil fuel combustion [5]. BC aerosols have been found to be contributing significantly to the atmospheric warming both globally and regionally [6]. China and India are large emission sources of BC from industry, residential, and transport sectors, including the incomplete fossil fuel combustion from sources such as open biomass burning and wood

*Address correspondence to this author at the Pulchowk Campus Institute of Engineering, Tribhuvan University, Lalitpur, Nepal; Tel: +97715543072; Fax: +97715525830; E-mail: rksharma2002@ioe.edu.np

E-ISSN: 1929-6002/17 burning cooking stoves $[7,8$, and 6$]$. BC represents the fraction of the carbonaceous material that absorbs visible light; $E C$ is graphitic carbon that absorbs in the visible range and it is not reduced to $\mathrm{CO}_{2}$ when heated to $800^{\circ} \mathrm{C}$ in an inert atmosphere. In principle, all EC is $B C$, but all $B C$ is not necessarily EC. BC aerosol particles have a detrimental impact on human health [9, 10]. BC acts as an indicator of air mass affected by anthropogenic pollution [11]. Recent studies suggest that $\mathrm{BC}$ can alter the cloud lifetime [12], precipitation pattern [13], reflectivity and melting of snow and ice [14]. Since most of the BC particles are in the fine particle size mode $[15,16]$, dry removal rate is small [17]. [18] showed BC concentration decreased abruptly after precipitation due to scavenging affects.

Solar radiation at the earth's surface is the ultimate energy source for life on planet. Clouds and aerosols are regarded as the most important one to explain the diming and brightening phenomenon. Atmospheric aerosols can directly modify surface solar radiation by scattering or absorbing solar radiation during its path from the top of the atmosphere to the surface of the earth.

Nepal, the Himalayan land- locked country is situated between two giant developing countries India and China, which are considered as major contributor 
of carbonaceous aerosol in the global contest. To have a snap- shot of EC, BC and total solar radiation, Kathmandu, the capital city of the country, and Biratnagar, the industrial city, are considered in this studied. In the past, various works regarding the monitoring of air pollution in Kathmandu had been done. However, Biratnagar is yet to be explored in this aspect. Present study will provide a comparative knowledge of carbonaceous aerosols and total solar radiation at Kathmandu and Biratnagar which are two representative sites of valley and flat land in the country respectively.

\section{EXPERIMENTAL DETAILS}

\subsection{Study Area}

Kathmandu valley is located between $27^{\circ} 37^{\prime} 30^{\prime \prime} \mathrm{N}$ and $27^{\circ} 45^{\prime} 0^{\prime \prime} \mathrm{N}$ latitude and $85^{\circ} 15^{\prime} 0^{\prime \prime} \mathrm{E}$ and $85^{\circ} 22^{\prime} 30^{\prime \prime}$ E longitude. The base of valley is about 1350 meters above sea level and covers about 340 square kilometer area. The cross section of the valley is about $20 \mathrm{~km}$ north to south and $30 \mathrm{~km}$ east to west. This valley has a bowl like structure surrounded by four major hilly peaks namely Shivapuri, Phulchowki, Nagarjun and Chandragiri at an elevation of more than $500 \mathrm{~m}$ from its base. Kathmandu valley is surrounded by major mountains in the northern side and consists of three major cities: Kathmandu, Bhaktpur and Lalitpur. At present, the population of the valley is 2.51 million [19].
It is the main political and administrative center, a major tourist gateway, and an economically strategic location of the country. High population growth, dramatic land use changes, and socioeconomic transformations have brought the paradox of rapid urbanization and environmental consequences to the valley.

The second study site Biratnagar is a submetropolitan city located at $26^{\circ} 28^{\prime} 60^{\prime \prime} \mathrm{N} 87^{\circ} 16^{\prime} 60^{\prime \prime} \mathrm{E}$. It is a flat land situated at the border with India and is, therefore, a major center for trade and commerce with India. This site is linked with Indian state "Bihar" which is an industrial state full of coal mines and mine industries. According to 2011 Center Bureau of Statics (CBS) Nepal census data, the population of Biratnagar is about 0.2 million and is, therefore, fourth largest city of Nepal after Kathmandu. Number of industries registered in this area are 295 [20]. The study sites are shown in Figure 1.

\subsection{Instruments Used}

Black carbon concentration was continuously measured using an aethalometer AE 31 manufactured by Magee Scientific USA. The aethalometer is an instrument that provides a real time read out of the EC or $\mathrm{BC}$ aerosol particles in air stream. The instrument aspirates ambient air using its inlet tube. Black carbon mass concentration is estimated by measuring the

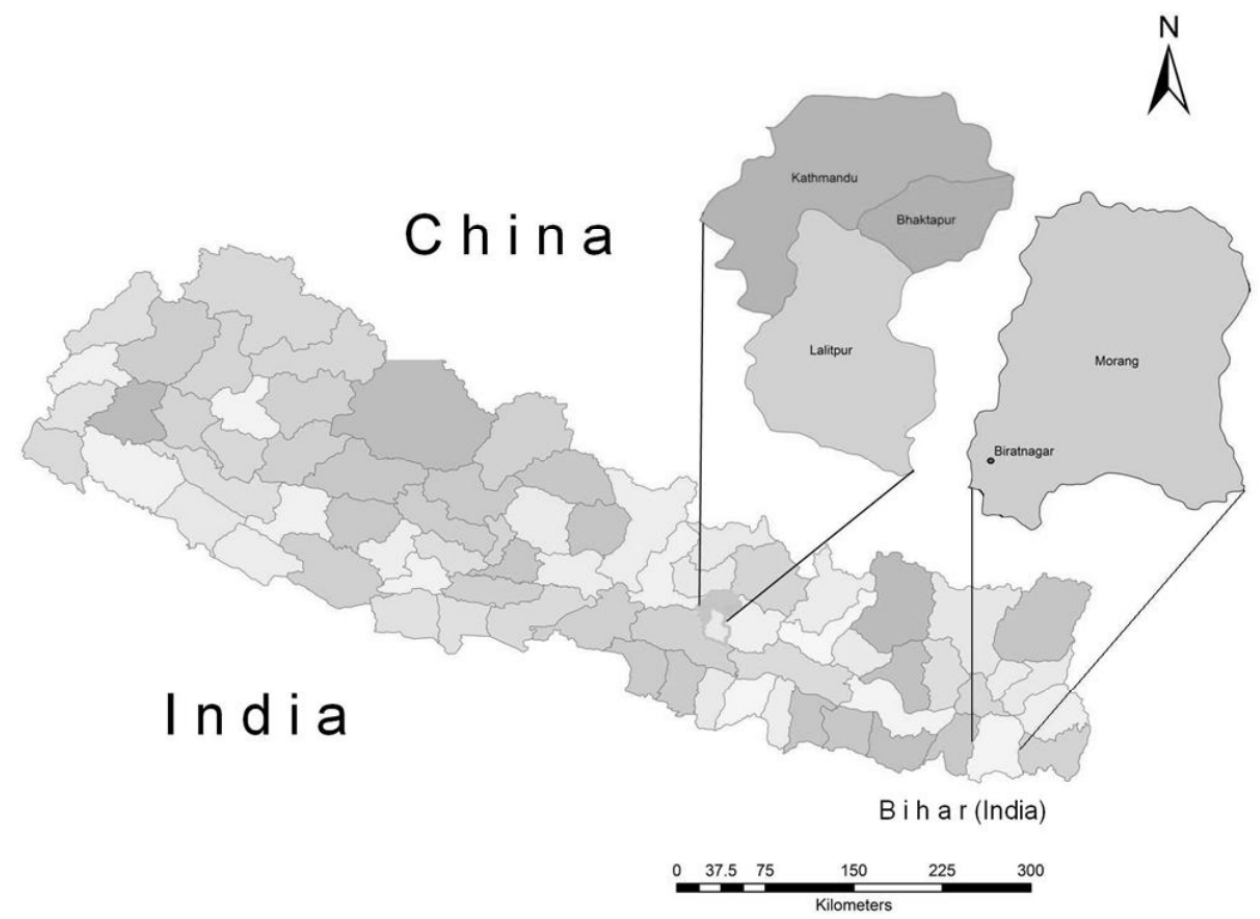

Figure 1: Map of Nepal showing the location of study sites Kathmandu and Biratnagar. 
change in the transmittance of a quartz filter tape, on to which particles impinge. The instrument was placed in operation at the time interval of 5 minutes, round the clock with a flow rate of 2 liters per-minutes (LPM). These data are automatically recorded in the flash card of the instrument and displayed on the screen. Five minute's data obtained were used for making hourly, daily, monthly and seasonal average calculation for the interpretation. This technique is reported to have shown good comparison with the other ones used for monitoring $\mathrm{BC}$ particles like coefficient of haze tape sampler, particle soot absorption photometer, and thermal oxidation/reflectance technique [21, 22]. The calibration of the flow rate is done quarterly at normal condition. However, when it became noisy during continuous operation, the flow rate was calibrated accordingly. More details on the instrument and the principle of operation are given elsewhere [23, 24].

Kipp and Zonen CMP6 pyranometer was used for the measurement of global solar radiation on a horizontal surface. The CMP6 pyranometer has wide spectral range of instrument from $319 \mathrm{~nm}$ to $2800 \mathrm{~nm}$. The operating temperature is from $-40^{\circ} \mathrm{C}$ to $80^{\circ} \mathrm{C}$. The sensitivity of instrument and field of view are 5 to $15 \mu \mathrm{V} / \mathrm{W} / \mathrm{sq}$. $\mathrm{m}$ and $180^{\circ}$ respectively. All the measured data are recorded by LOGBOX SD data logger within a minute resolution for 24 hours. It can be used at all weather conditions and collects the data at real time.

\section{RESULT AND DISCUSSION}

In the present study two sites Kathmandu (valley) and Biratnagar (Flat land 'Terai') are considered for temporal and spatial variation of EC and BC. Data of both the carbonaceous aerosols for Kathmandu are available from November 2008 onwards while it is only from January to May 2011 for Biratnagar so, in the present paper only five months data are analyzed and interpreted. Total solar radiation data of the same year of Kathmandu and Biratnagar from January to April are compared to study their variation in these two different cities and the effect of aerosols on it.

\subsection{Monthly Variation}

The monthly variation of $\mathrm{EC}$ and $\mathrm{BC}$ in the observed months of both the cities are distinct with highest concentration in January and lowest on May. The monthly average EC values at Biratnagar and Kathmandu in January was 20.2 and $13.7 \mu \mathrm{g} / \mathrm{m}^{3}$ while $\mathrm{BC}$ as 19.5 and $14.5 \mu \mathrm{g} / \mathrm{m}^{3}$ respectively. The $\mathrm{EC}$ value of Biratnagar is higher than $B C$ value indicating consumption of more biomass fuel than fossil fuel. In Kathmandu, BC is usually higher.

Monthly box and whisker plot for the study period for the concentrations of $\mathrm{EC}$ and $\mathrm{BC}$ are given in Figures 2 and 3 respectively. The square sign () denotes the monthly mean, the horizontal bar represents the monthly median and the hatched boxes contain $25^{\text {th }}$ to $75^{\text {th }}$ percentile range of values for that month. Outliers are shown as asterisk $\left(^{*}\right)$ for the month. It can be seen that the concentration of EC and BC both are higher in the first two months (January February) in Biratnagar which are winter. These components are higher in Kathmandu in rest of the months (March, April and May). Further it can be seen that the variability in the concentrations of EC and $B C$ both are higher in those months when monthly values are higher and low when the values are less. Moreover the high concentration of $\mathrm{EC}$ and $\mathrm{BC}$ in winter months are attributed to consumption of high amount of biofuel and fossil fuel for the internal heating and other activities.

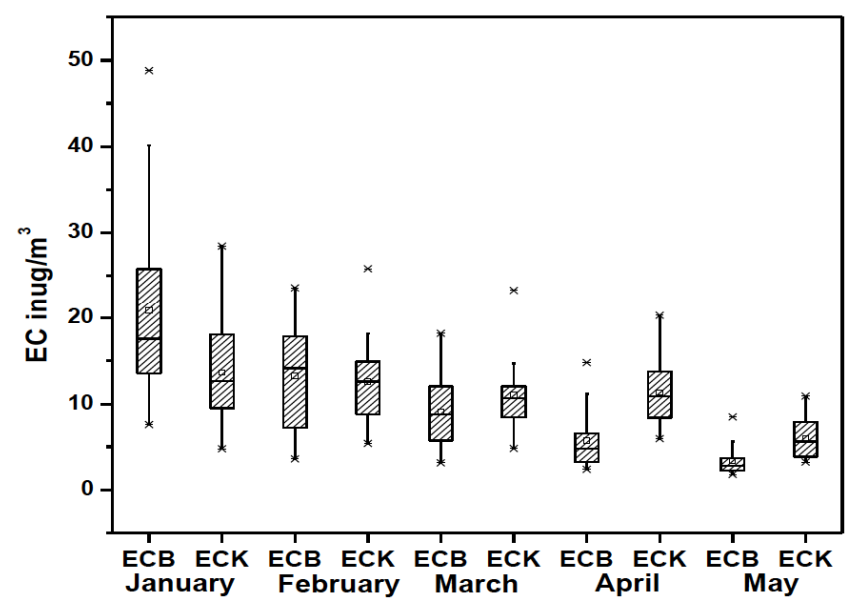

Figure 2: Monthly distributions of EC concentrations as displayed in box and whisker plot.

From the wind rose plot of Biratnagar, Figure 4, it is clear that percent of calm wind (less than $0.5 \mathrm{~m} / \mathrm{s}$ ) is comparatively higher in January and February than the rest of the months. In addition, wind is blowing SW, WSW during January and February while it is ENE and $E$ in March, April and May. The neighboring state Bihar in India is also a flat land and consumes huge amount of coal for industries and thermal power. Transboundary transportation of aerosols is dominating in addition to consumption of high amount fuel for winter heating. Hence, high concentration of carbonaceous aerosols is found in Biratnagar. In the case of remaining three preceding months, comparatively less amount of fuel is consumed for 


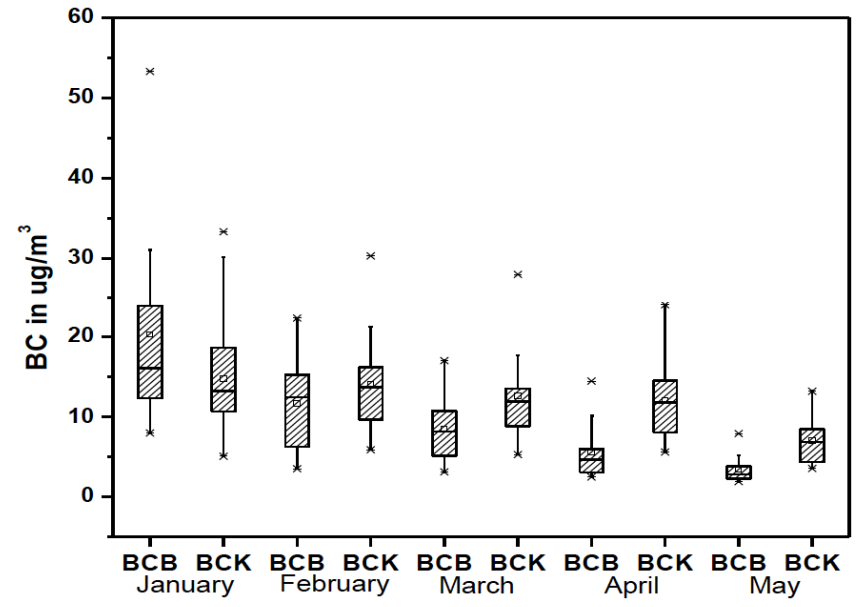

Figure 3: Monthly distributions of BC concentrations as displayed in box and whisker plot.

domestic activity than in winter. In addition wind is blowing from ENE and $E$, of the rural hilly area of Nepal. This is one of the causes of flushing of EC and $\mathrm{BC}$ from the study site towards boundary Indian area so the concentration of carbonaceous aerosols is less in these months.

Bowled shaped topography of Kathmandu valley has some limitation for the flushing of aerosols from the city. The air in Kathmandu in January and February becomes dry and cold. Sometimes temperature drops even below $0^{\circ} \mathrm{C}$. Kathmandu inhabitants are, therefore, expected to use more fuel (wood fuel, fuel gas and gasoline) than in the rest of the months for space heating. This winter activity is also partially responsible for the increase of Carbonaceous aerosols $E C$ and $B C$ in one hand while on the other, temperature inversion and low wind speed are other governing factors in the variation of carbonaceous aerosol concentration in these months. In rest of the months from March to April (premonsoon), temperature of the valley gradually increases which reduces the consumption of extra fuel for space heating. In addition to this, active wind also increases in these months. So carbonaceous aerosols concentration gradually decreases.

The daily average EC and BC in Biratnagar is shown in Figure 5. It also shows error bar for each day. Variation of EC and BC is very significant in January and February and become almost homogenous in the rest of the months. Very low values of $E C$ and $B C$ in few days of May and April are attributed to significant rain recorded in those days.

Figure 6 represents daily average carbonaceous aerosols EC and BC of Kathmandu site with error bar for each day. Variations of carbonaceous aerosols are comparatively homogenous for the whole period than Biratnagar site. The difference is due to topography and meteorology of the studied sites. The highest peak of EC and BC both were recorded on Shivaratri festival,

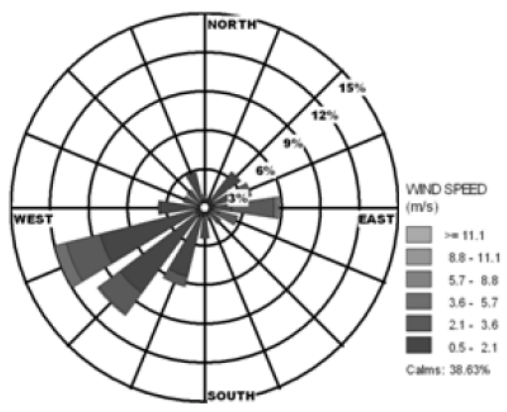

a

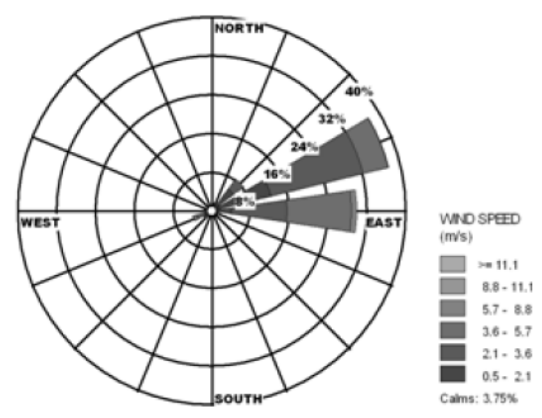

d

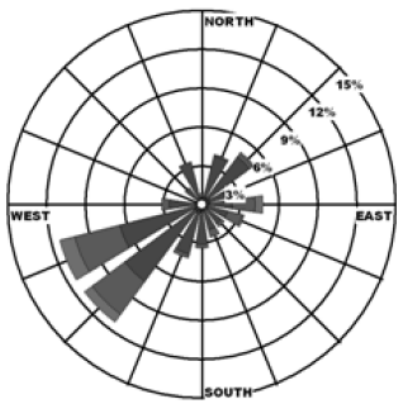

b

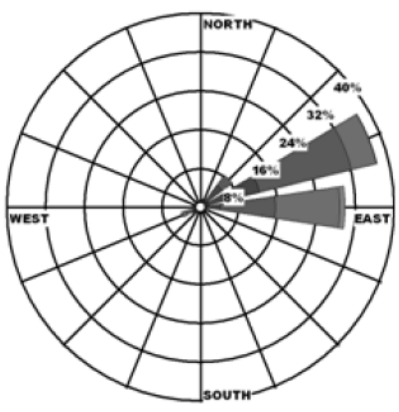

e
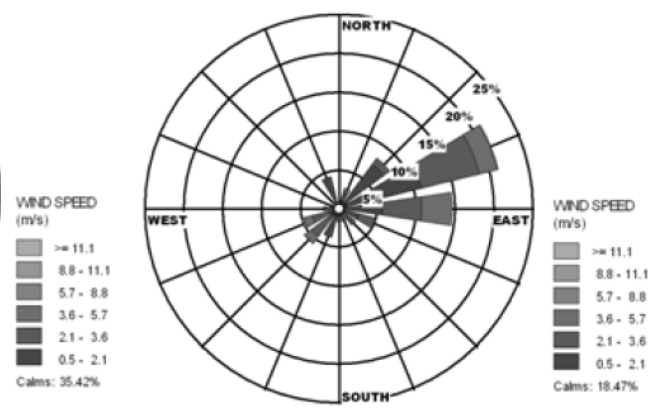

C

Figure 4: Wind rose diagrams for Biratnagar from January-May 2011(a-e). 

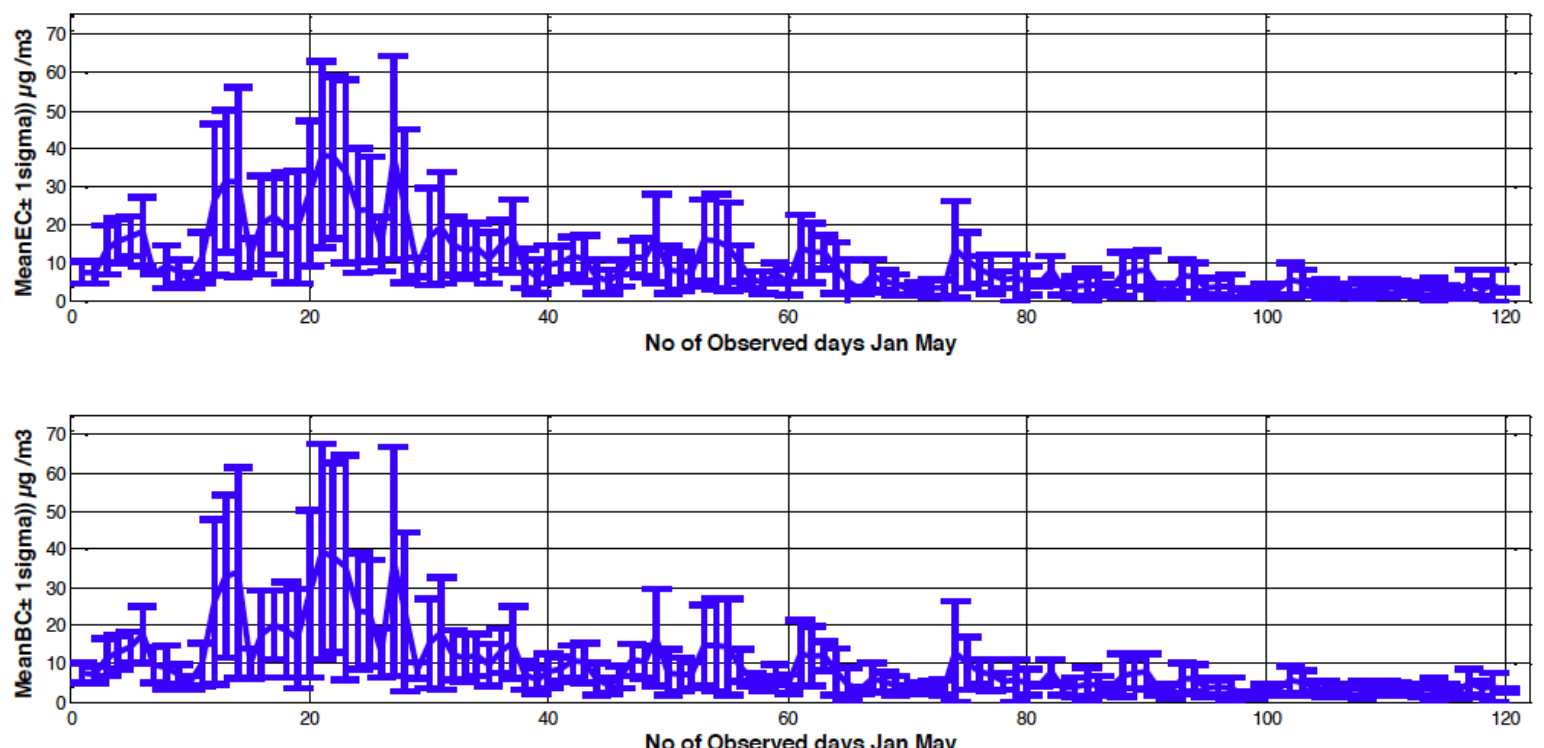

Figure 5: Daily average EC and BC concentration from January to May at Biratnagar.
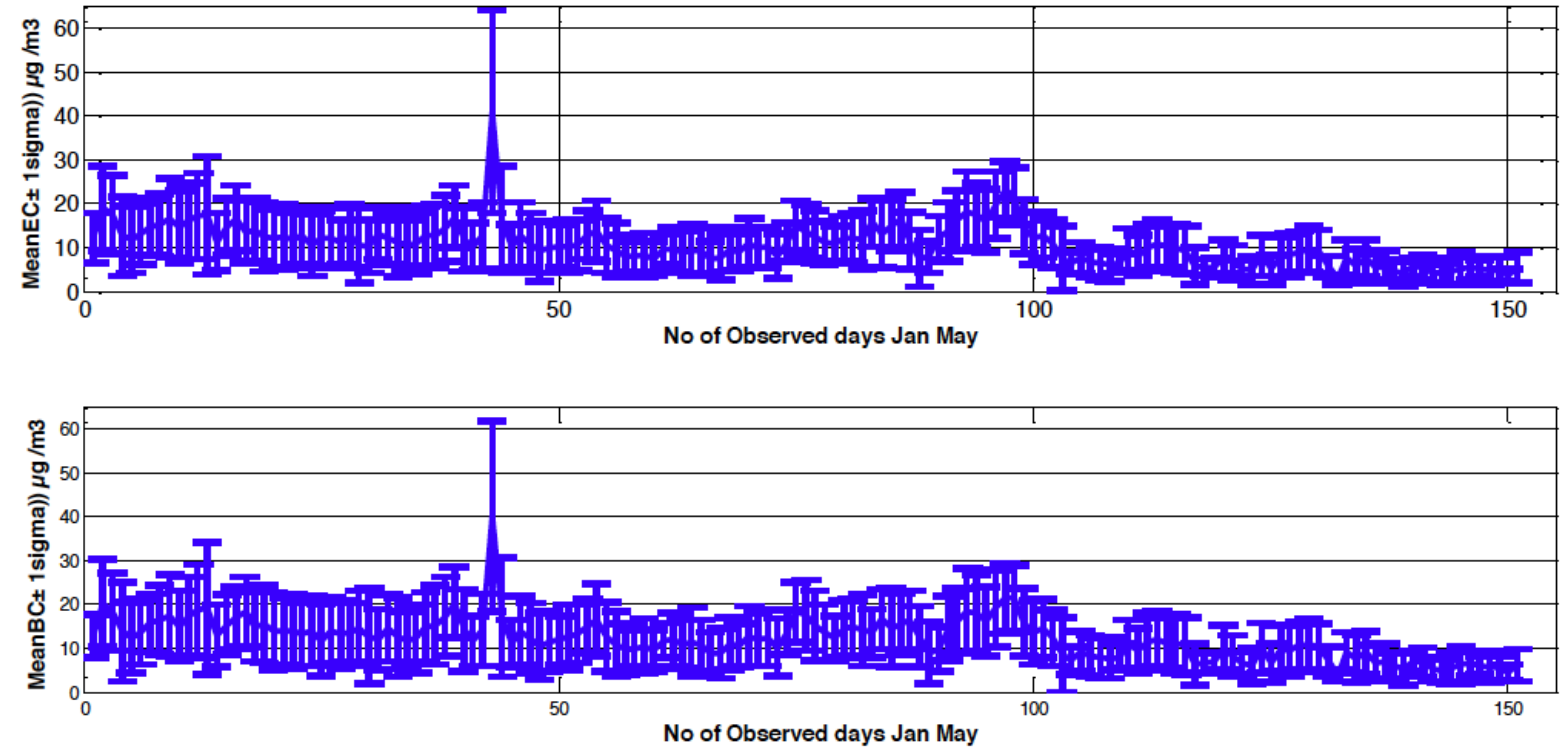

Figure 6: Daily average EC and BC concentration from January to May at Kathmandu.

12 February, which is a typical wood burning festival of Hindus. This infers the effect of local event in the variation of aerosols.

\subsection{Diurnal Variation}

Five minute interval data of aethalometer was used for making hourly average. The average hourly EC and $B C$ value for each month was plotted and is shown in Figure 7 for Biratnagar. A distinct diurnal variation of both $E C$ and $B C$ at Biratnagar was observed. Two high concentration peaks of carbonaceous aerosols are observed one at about 8:00 morning and another at about 20:00 late evening local time (local time 5:45 ahead of UTC). At Biratnagar, evening peaks are greater than the morning peak. The amplitude is largest in January and gradually decreases until May. Further, it has been observed that EC peak in most of the observed months at this site are greater than BC peak value. These values of carbonaceous aerosols and higher peak in the evening than in the morning shows that more domestic, industrial and on road activities are there in the evening.

The Figure 8 shows the similar curve for Kathmandu as in Figure 7. As in Biratnagar, a distinct diurnal variation is observed. Two peaks are observed (one in the morning around 09:00 and another in the 

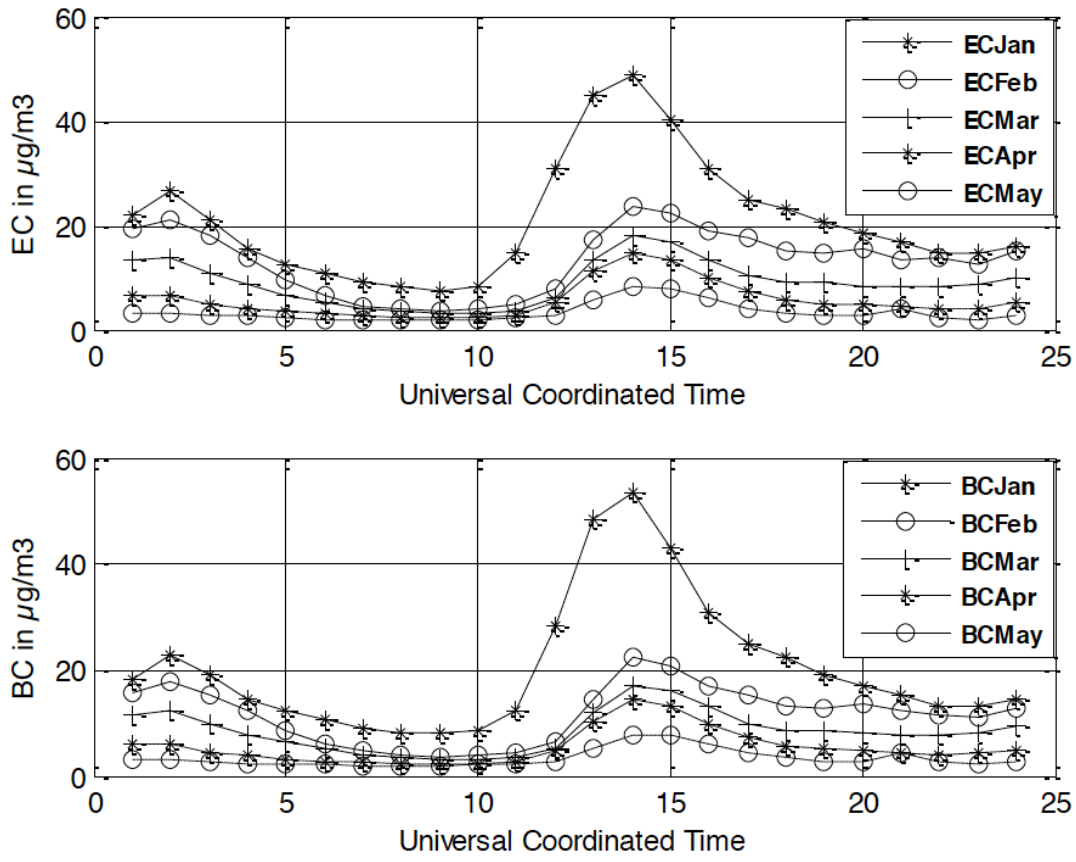

Figure 7: Diurnal Variations of $E C$ and $B C$ in Biratnagar from January to May.

evening around 20:00 local time). Contrary to Biratnagar, morning peak is greater than evening showing pronounced anthropogenic carbonaceous aerosols producing activities in the morning than in the evening in Kathmandu.

A comparison of diurnal wind and diurnal carbonaceous aerosols of both the sites is shown in Figure $\mathbf{9 , 1 0}$ and $\mathbf{1 1}$. High concentration of carbonaceous aerosols ( $E C$ and $B C$ ) is observed when the wind speed is low. In Biratnagar, the maximum wind speed is slightly above $2.5 \mathrm{~m} / \mathrm{s}$ during $10: 00$ 13:00 local time where the value of carbonaceous aerosols are minimum. This pattern is nearly followed in Kathmandu site as well. However, the maximum wind speed value is below $2.5 \mathrm{~m} / \mathrm{s}$. Moreover, the minimum $\mathrm{EC}$ and $\mathrm{BC}$ value is comparatively less than in Biratnagar. It can be concluded that irrespective of the location of the study site, wind speed and its pattern influences the variation in carbonaceous
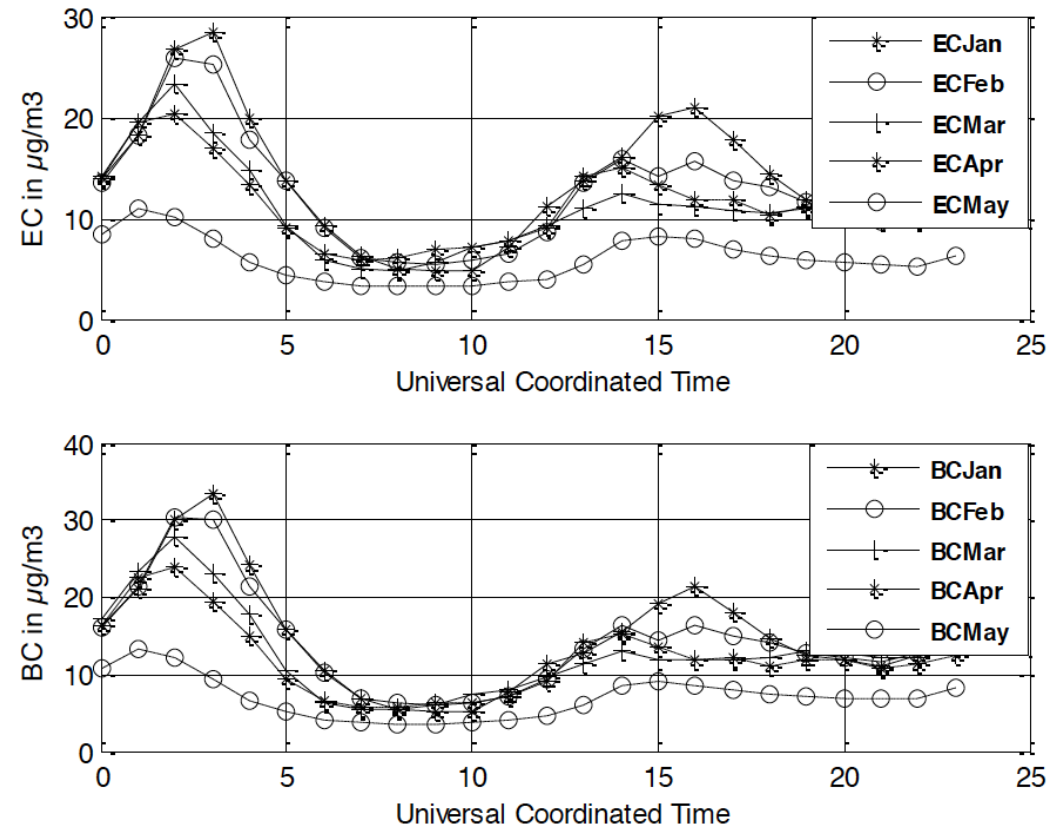

Figure 8: Diurnal Variations of EC and BC in Kathmandu from January to May. 


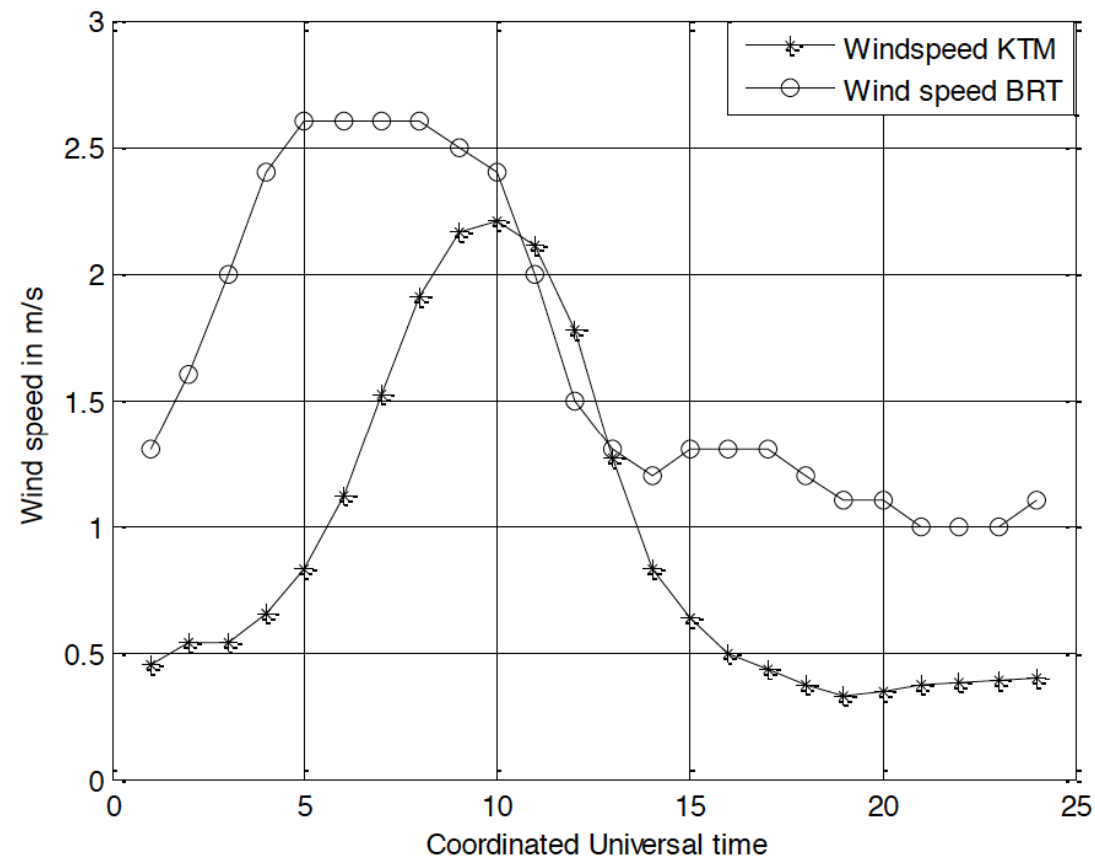

Figure 9: Diurnal variation of Wind speed in Kathmandu and Biratnagar January to May.

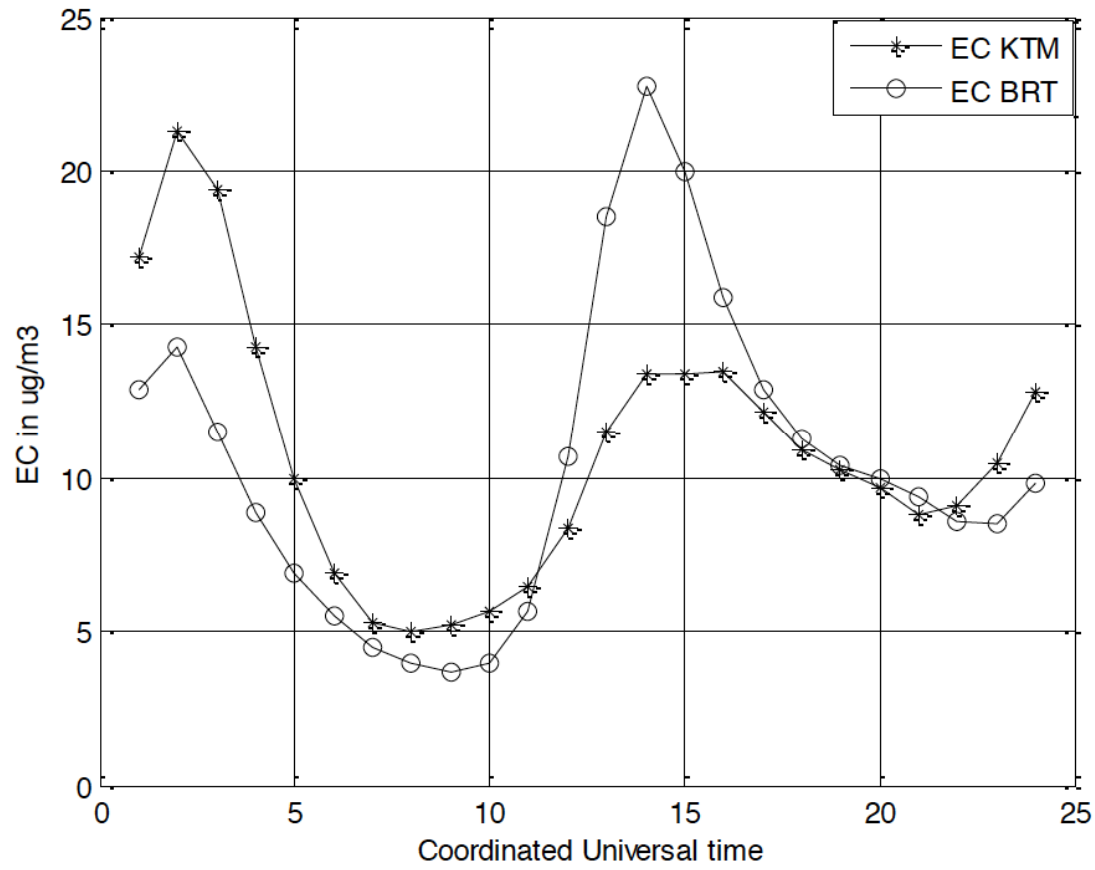

Figure 10: Diurnal trends of EC in Kathmandu and Biratnagar from January to May.

aerosols. Interestingly figures also represent that evening peak of $E C$ and $B C$ both are higher than morning in Biratnagar while it is just opposite in Kathmandu. The topography of Kathmandu is totally different from that of Biratnagar flat land (Terai). It is equally possible that the accumulated carbonaceous aerosols of previous day are reflected in next day morning due to bowl shaped topography of the valley. In contrary to this in flat land Biratnagar same day activities of carbon emission is reflected in the evening with high peak.

Total solar radiation in both the sites represent similar trend with maximum value within 12:00 to $13: 00$ in Biratnagar while in Kathmandu, it is around 12:00 local time. A distinct diurnal variation of total solar radiation as carbonaceous aerosols is observed indicating its highest value when aerosols concentration is minimum. 


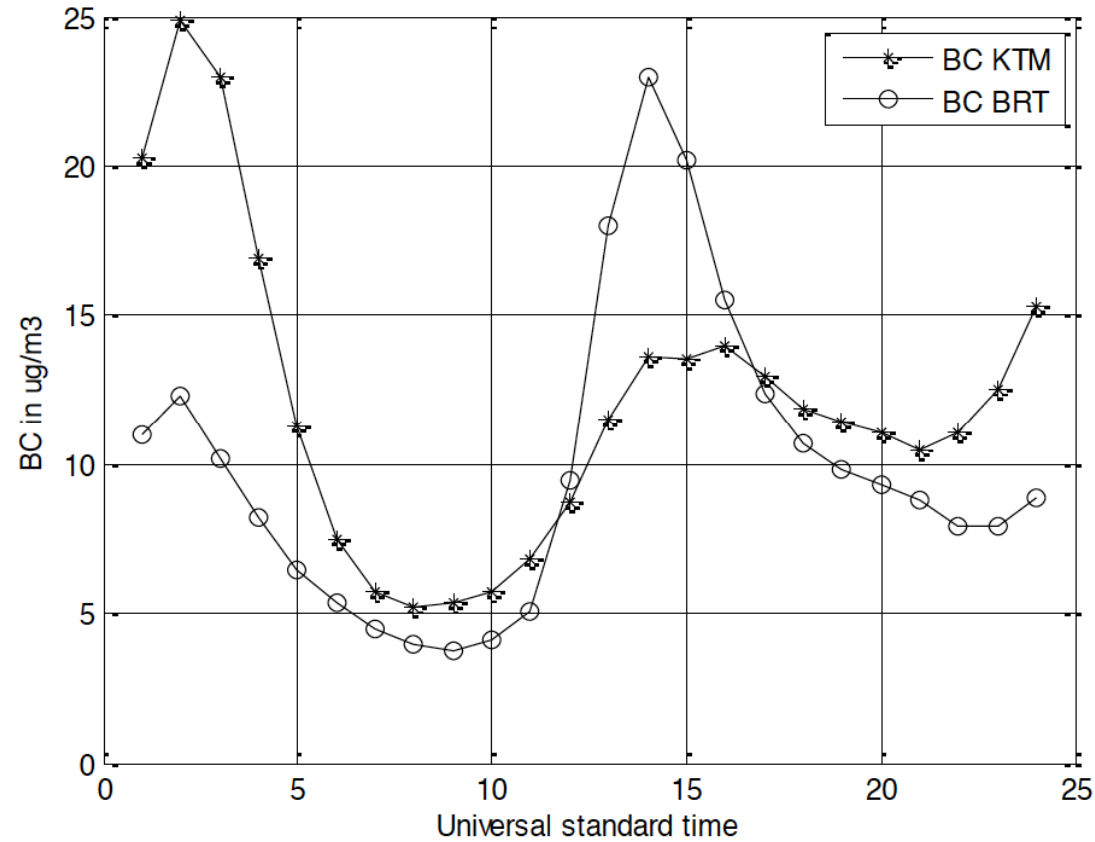

Figure 11: Diurnal trends of $B C$ in Kathmandu and Biratnagar January to May.

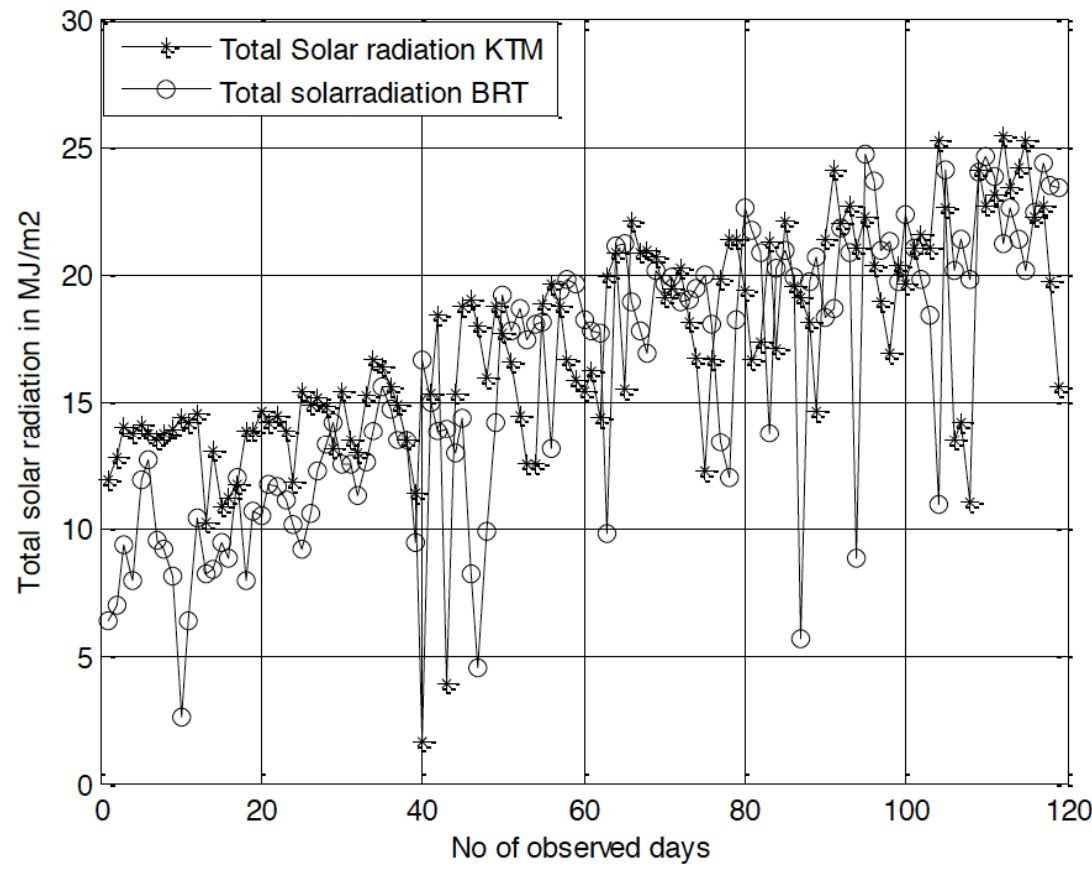

Figure 12: Daily variation of total solar radiation in Kathmandu and Biratnagar (January to April).

The total solar radiation of a particular place depends on altitude, aerosols and sunshine hours. The monthly average solar radiation of Biratnagar for January to April was 9.9, 14.6, 18.1, 21.0 $\mathrm{MJm}^{-2}$ respectively. In the same way, in Kathmandu from January to April, it was $13.5,15.1,18.6,20.9 \mathrm{MJm}^{-2}$. As carbonaceous aerosols value in both the study site is decreasing from January to April its contribution on solar radiation is gradually decreasing. Furthermore, except April, the solar radiation values are more in Kathmandu than Biratnagar. This is because of location of Kathmandu at higher altitude than Biratnagar.

Monthly box and whisker plot for the study period January to May for total solar radiation is given in Figures 13. The square sign ( $\left.{ }^{\circ}\right)$ denotes the monthly mean, the horizontal bar represents the monthly median and the hatched boxes contain $25^{\text {th }}$ to $75^{\text {th }}$ percentile range of values for that month. Outliers are 


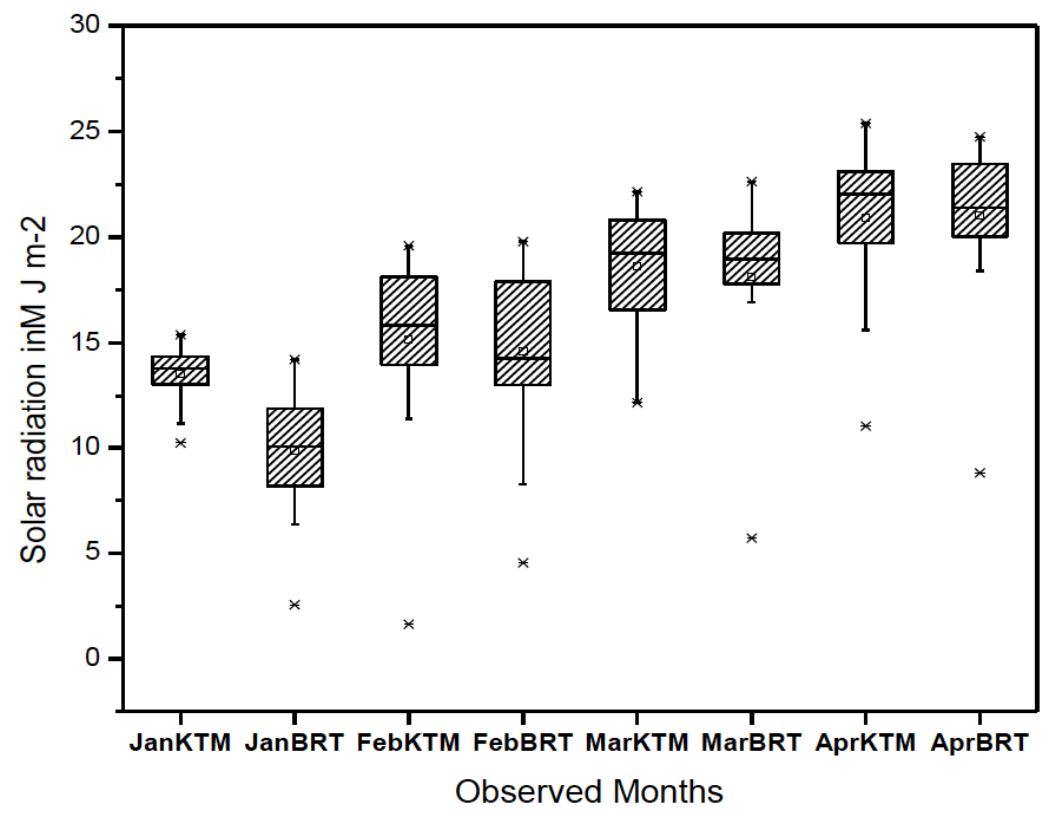

Figure 13: Monthly distribution of solar radiation as displayed in box and whisker plot.

Table 1: Daily Mean of EC, BC and Solar Radiation on Working Days and Weekend

\begin{tabular}{|c|c|c|c|c|c|c|c|c|}
\hline Place & Component & Saturday & Sunday & Monday & Tuesday & Wednesday & Thursday & Friday \\
\hline \hline Biratnagar & $\mathrm{EC} \mu \mathrm{g} / \mathrm{m}^{3}$ & 10.2 & 8.8 & 9.2 & 11.0 & 11.1 & 10.9 & 11.8 \\
\hline Biratnagar & $\mathrm{BC} \mu \mathrm{g} / \mathrm{m}^{3}$ & 9.8 & 8.2 & 8.6 & 10.0 & 10.5 & 10.2 & 11.6 \\
\hline Biratnagar & $\mathrm{Sol} \mathrm{rad} \mathrm{M} \mathrm{J} \mathrm{m}$ & 16.2 & 16.2 & 14.6 & 15.6 & 16.6 & 15.7 & 15.9 \\
\hline Kathmandu & $\mathrm{EC} \mu \mathrm{g} / \mathrm{m}^{3}$ & 12.0 & 11.0 & 11.3 & 11.0 & 10.5 & 11.1 & 12.4 \\
\hline Kathmandu & $\mathrm{BC} \mu \mathrm{g} / \mathrm{m}^{3}$ & 12.0 & 11.4 & 11.5 & 11.5 & 10.7 & 11.6 & 12.8 \\
\hline Kathmandu & $\mathrm{Sol} \mathrm{rad} \mathrm{M} \mathrm{J} \mathrm{m}^{2}$ & 16.9 & 16.7 & 17.1 & 16.0 & 17.7 & 18.2 & 16.5 \\
\hline
\end{tabular}

shown as asterisk $\left(^{*}\right)$ for the month. It can be seen from the figure that there is gradual increase in the value of total solar radiation from January to May in both sites. Minimum value (lower outliers) is nearly $2 \mathrm{MJ} / \mathrm{m}^{2}$ in the cloudy and overcast days.

\subsection{Correlation of Solar Radiation and Wind Speed with Carbonaceous Aerosols}

There is a meaningful anti-correlation of solar radiation and carbonaceous aerosols (EC or $\mathrm{BC}$ ) with $r=-0.75$ for Biratnagar and $r=-0.63$ for Kathmandu. This particular observation infers that $\mathrm{EC}$ and $\mathrm{BC}$ both existing in the atmosphere play a significant role in the reduction of solar radiation. Similarly significant anticorrelation of EC and wind speed is observed in Biratnagar with $r=-0.77$.

\subsection{Variation of EC and BC in Working Days and Weekend}

On the basis of six working days (Sunday-Friday) and a weekend Saturday, EC and BC data for the observed period were grouped in seven groups. These daily average of seven days are analyzed to find out the variation of carbonaceous aerosols in working days and weekend. The same type of system was also applied for daily solar radiation value to explore its variation in working days and weekend. Average Friday $E C$ and $B C$ value was the highest on both the sites irrespective of the location. This is because of extra fuel consuming activities during the start of weekend. Weekend value is not the lowest value inferring most of the anthropogenic aerosol producing activities remain common even at weekend. Pronounced relation of total solar radiation and carbonaceous aerosols is not seen in this grouped analysis.

\section{CONCLUSIONS}

The monthly average concentration of carbonaceous aerosols (EC and BC) represents distinct variation in both the sites. Concentration of the aerosols gradually decreases from January to May irrespective to the study sites. 
Highest concentration of $\mathrm{EC}$ and $\mathrm{BC}$ are observed during January in Biratnagar than in Kathmandu showing transboundary aerosols from the neighboring industrial state of India, Bihar.

Monthly average value of $E C$ is higher than $B C$ at Biratnagar showing consumption of more biofuels than fossil fuel for domestic, industrial and other urban activities. Kathmandu shows reverse order which suggests the domination of fossil fuel for domestic, industrial and other activities.

Monthly average solar radiation value at both the sites show similar pattern with highest value on May and lowest on January. In addition to this, the total solar radiation value at Kathmandu is slightly more than that of Biratnagar because of its higher altitude.

Diurnal variation of aerosols is very distinct at both the sites with two high peaks one at morning about 9:00 and another about 20:00 late evening local time with minimum value in the afternoon.

At Biratnagar, the evening peak was larger than morning while it was just opposite for Kathmandu referring more on road and industrial activities at evening than morning in the former while it is more in the morning in the later.

Total solar radiation also represents significant diurnal variation with peak value from 12-13:00 at both the places. Meaningful anti-correlation of carbonaceous aerosols $(E C B C)$ with wind speed and solar radiation is observed in both the study sites

Concentration of carbonaceous aerosols analyzed for working days and weekend shows maximum values on Friday showing extra fuel consuming activities like driving, barbeque, etc. on this day than in rest of the five days before the weekend.

\section{ACKNOWLEDGEMENTS}

The author is thankful to SAHR for providing instruments and logistic support for the present paper. Mr. Jayendra Shrestha and Suranjan Sharma are also acknowledged for their support in data monitoring for this paper. I am also thankful to Rupnarayan Shrestha for his valuable support.

\section{REFERENCES}

[1] Lim HJ, Turpin BJ. Origins of primary and secondary organic aerosols in Atlanta; Results of time resolved measurements during the Atlanta Supersite experiment. Environ Sci Techol 2002; 36: 4489-4496.

https://doi.org/10.1021/es0206487
Lin P, Hu M, Deng Z, Slanina J, Han S, Kondo Y, Takegawa $N$, Miyazaki $Y$, Zhao $Y$, Sugimoto $N$. Seasonal and diurnal variations of organic carbon in $\mathrm{PM}_{2.5}$ in Beijing and the estimation of secondary organic carbon. J Geophys Res Atmos 2009; 114: D00G11. https://doi.org/10.1029/2008JD010902

[3] Cachier H. Combustion carbonaceous aerosols in the atmosphere: implications for ice core studies. In; Robert J D (Ed) Ice core studies of global Biogeochemical cycles NATO. ASI Series Springer, Berlin 1995; pp. 313-346. https://doi.org/10.1007/978-3-642-51172-1 17

[4] Hansen ADA, Rosen H, Norakov T. The aethalometer: an instrument for the real time measurement of optical absorption by aerosol particles. Sci Total Environ 1984; 36: 191-196.

https://doi.org/10.1016/0048-9697(84)90265-1

[5] Cooke WF, Wilson JJN. A global black carbon aerosol models. J Geophys Res 1996; 101: 19395-19409.

https://doi.org/10.1029/96JD00671

[6] Ramanathan V, Carmichael G. Global and regional climate changes due to black carbon. Nat Geosci 2008; 1: 221-227. https://doi.org/10.1038/ngeo156

[7] Bond TC, Streets DG, Yarber KF, Nelson SM, Woo JH Klimnot $Z$. A technology based global inventory of black and organic carbon emissions from combustion. J Geophys Res 2004; 109: D14203. https://doi.org/10.1029/2003JD003697

[8] Ramanathan V, Li F, Ramana MV, Praveen PS, Kim D, Corrigan CE, Nguyen $\mathrm{H}$, Stone EA, Schauer JJ, Carmichael GR, Adhikari B, Yoon SC. Atmospheric brown clouds: hemispherical and regional variations in long range transport, absorption, and radiative forcing. J Geophys Res 2007; 112: D22S21. https://doi.org/10.1029/2006JD008124

[9] Samet J, Dominici F, Crriero F, Coursac I, Zeger S. Fine particulate air pollution and mortality in 20 U.S cities, 19871994. N Engl J Med 2000; 343: 1742-1749.

https://doi.org/10.1056/NEJM200012143432401

[10] Pope A, Burnett R, Thun M, Calle E, Krewski D, Ito K Thurston G. Lung cancer, cardiopulmonary mortality and long-term exposure to fine particulate air pollution. JAMA 2002; 287: 1132-1141 https://doi.org/10.1001/jama.287.9.1132

[11] Penner JE. Carbonaceous aerosols influencing atmospheric radiation: Black and organic carbon. In: aerosol forcing of climate. R.J. Charlson and J. Heintzenberg (eds.) John Wiley and sons Ltd 1995; 91-108.

[12] Acerman AS, Toon OB, Stevens DE, Heymsfield AJ Ramanathan V, Welton EJ. Reduction of tropical cloudiness by soot. Science 2000; 288: 1042-1047. https://doi.org/10.1126/science.288.5468.1042

[13] Menon S, Hansen J, Nazarenko I, luo YF. Climate effects of black carbon aerosols in China and India. Science 2002; 297: 2250-2253.

https://doi.org/10.1126/science.1075159

[14] Hansen J, Nazarenko L. Soot climate forcing via snow and ice albedos. Proc Natl Acad Sci 2003; 101: 123-428.

[15] Ogren JA, Charlson RJ. Elemental carbon in the atmosphere: cycle and life time. Tellus 1983; 35b: 241-254. https://doi.org/10.1111/j.1600-0889.1983.tb00027.x

[16] Penner JE, Dickinson RE, O'Neill CA. Effects of aerosol from biomass burning on the global radiation budget. Science 1992; 256: 1432-1434 https://doi.org/10.1126/science.256.5062.1432

[17] Ogren JA, Groblicki PJ, Charlson RJ. Measurement of the removal rate of elemental carbon from the atmosphere. Sci Total Environ 1984; 36: 329-338.

https://doi.org/10.1016/0048-9697(84)90284-5 
[18] Bahrmann CP, Saxena VK. The influence of air mass history on black carbon concentration in the southeastern Unites States. J Geophys Res1998; 103: 23153-23161. https://doi.org/10.1029/98JD02475

[19] Central Bureaus of Statics (CBS), 2011 Web Address: http://www.cbs.gov.np/. Central Bureau of Statistics, Nepal Government, as of 17 May 2012.

[20] Central Bureaus of Statics (CBS), 2006. Web Address: http://www.cbs.gov.np/. Central Bureau of Statistics, Nepal Government, as of 17 May 2012.

[21] Allen GA, Lawrence J, Koutrakis P. Field validation of a semicontinuous method for aerosol black carbon (aethalometer) and temporal patterns of summertime hourly black carbon measurements in southwestern PA. Atmos Environ 1999; 33: 817-823. https://doi.org/10.1016/S1352-2310(98)00142-3
[22]

Babich P, Wang P, Allen G, Sioutus C, Koutrakis P.Development and evaluation of a continuous ambient PM mass monitor. Aerosol Sci Technol 2000; 32: 309-324. https://doi.org/10.1080/027868200303641

[23] Hansen ADA, Rosen H, Norakov T. The aethalometer: an instrument for the real time measurement of optical absorption by aerosol particles. Sci Total Environ 1984; 36: 191-196.

https://doi.org/10.1016/0048-9697(84)90265-1

[24] Weingartner E, Saathof $H$, Schnaiter $M$, Streit N, Bitnar B, Baltensperger $U$. Absorption of light by soot particles: Determination of the absorption coefficient by means of Aethalometers. J Aerosol Sci 2003; 34: 1445-1463. https://doi.org/10.1016/S0021-8502(03)00359-8 